\title{
Correction to: Framework for the Analysis of Smart Cities Models
}

Elsa Estrada, Rocio Maciel, Adriana Peña Pérez Negrón, Graciela Lara López, Víctor Larios, and Alberto Ochoa

\section{Correction to: \\ Chapter "Framework for the Analysis of Smart Cities Models" in: J. Mejia et al. (Eds.): Trends and Applications in Software Engineering, AISC 865, https://doi.org/10.1007/978-3-030-01171-0_24}

In the original version of the book, the following belated correction have been incorporated: The author name "Graciela López Lara" has been changed to "Graciela Lara López" in the Frontmatter and in Chapter "Framework for the Analysis of Smart Cities Models". 